\title{
PERLINDUNGAN HUKUM TERHADAP MASYARAKAT DI SEKITAR KEGIATAN USAHA PT PERTAMINA GEOTHERMAL ENERGY (PT PGE) HULU LAIS DI KABUPATEN LEBONG DITINJAU DARI ASPEK HUKUM LINGKUNGAN
}

\author{
Tri Andika ${ }^{1}$ \\ Deli Waryenti ${ }^{2}$ \\ P. Ekowati Suryaningsih ${ }^{3}$ \\ Fakultas Hukum Universitas Bengkulu \\ ${ }^{1}$ andikatri@unib.ac.id \\ 2deliwaryenti@unib.ac.id \\ 3 nuning_bkl@yahoo.co.id
}

\begin{abstract}
People in several villages in the Lebong Tengah and South Lebong sub-districts of Lebong Regency have recently been anxious because of the landslide in Bukit Beliti which is the site of PT PGE's Hulu Lais cluster A. Landslides resulted in the death of 6 people and other material losses in the form of sinking fish ponds, rice fields and community gardens until crop failure. In addition, the source of drinking water for residents (PDAMs) in the two villages is also polluted, black, foamy and smelly. In the drilling process, PT PGE's machines also issued a loud sound, making the ground vibrate and emitting hot and white steam which caused the surrounding air to become hot. As a result, a number of plants in the surrounding gardens become dry and charred. Finally, in the drilling process PT PGE Hulu Lais also drained water from the Mubai river, so that the river water discharge drastically reduced. As a result, residents who have relied on river water for washing, bathing, irrigating rice fields and fish ponds, must find other water sources. For a civil settlement, PT PGE Hulu Lais has handed over a number of compensation to residents both to residents whose families died and residents whose fields or gardens were submerged in mud. Similarly, the Administration of the Environment Agency (DLH) has given several warnings to PT PGE. However, enforcement of environmental law from the aspect of criminal law has not been implemented due to the absence of PPNS staff in the Administration of the Environment Agency (DLH).
\end{abstract}

Keywords: Protection, Society, PT. PGE, Law, Environment

\begin{abstract}
ABSTRAK
Masyarakat di beberapa desa di kecamatan Lebong Tengah dan Lebong Selatan Kabupaten Lebong akhir-akhir ini resah karena terjadinya longsor di Bukit Beliti yang merupakan tempat kegiatan cluster A PT PGE Hulu Lais. Longsor mengakibatkan meninggalnya 6 orang dan kerugian materil lain berupa tenggelamnya kolam ikan, sawah, dan kebun warga hingga gagal panen. Selain itu sumber air minum warga (PDAM) di dua desa juga tercemar, berwarna hitam, berbusa dan berbau. Dalam proses pengeboran itu mesin-mesin PT PGE juga mengeluarkan suara
\end{abstract}


yang keras, membuat tanah bergetar serta mengeluarkan uap panas yang berwarna putih dan hitam sehingga menyebabkan udara sekitarnya menjadi panas. Akibatnya sejumlah tanaman di kebun sekitarnya menjadi kering dan hangus. Terakhir, dalam proses pengeboran itu PT PGE Hulu Lais juga menyedot air dari sungai Mubai, sehingga debit air sungai berkurang drastis. Akibatnya warga yang selama ini mengandalkan air sungai untuk mencuci, mandi, mengairi sawah dan kolam ikan, harus mencari sumber air lain. Untuk penyelesaian secara perdata, PT PGE Hulu Lais telah menyerahkan sejumlah ganti rugi kepada warga baik kepada warga yang keluarganya meninggal maupun warga yang sawah atau kebunnya terendam lumpur. Begitu pula secara administrasi Dinas Lingkungan Hidup (DLH) telah memberikan beberapa teguran kepada PT PGE. Namun penegakan hukum lingkungan dari aspek hukum pidana belum dilaksanakan karena tidak adanya tenaga PPNS di DLH.

Kata Kunci: Perlindungan, Masyarakat, PT. PGE, Hukum, Lingkungan

\section{Pendahuluan}

Kabupaten Lebong merupakan salah satu Daerah otonom di Provinsi Bengkulu dan beribukota di Tubei. Kabupaten Lebong dibentuk dari hasil pemekaran Kabupaten Rejang Lebong berdasarkan Undang-undang U No.39 Tahun 2003 tentang Pembentukan Kabupaten Lebong dan Kabupaten Kepahiang di Propinsi Bengkulu. Kabupaten ini terletak di posisi $105^{\circ}-108^{\circ}$ Bujur Timur dan $02^{\circ}, 65^{\prime}-$ 03ㅜ,60' Lintang Selatan di sepanjang Bukit Barisan serta terklasifikasi sebagai daerah Bukit Range pada ketinggian 500-1.000 di atas permukaan laut.

Secara administratif Kabupaten Lebong terdiri dari 115 Desa dan Kelurahan serta 13 Kecamatan dengan luas wilayah keseluruhan sebanyak 192.424 Ha. Dari total luas ini, seluas 134.834,55 Ha adalah Kawasan Konservasi dengan peruntukan untuk
Kawasan Taman Nasional Kerinci Sebelat 111.035,00 Ha, Hutan Lindung 20.777,40 Ha dan Cagar Alam 3.022,15 Ha. ${ }^{1}$

Lokasi Kabupaten Lebong berada pada posisi yang cukup strategis, yaitu berbatasan sebelah utara dengan Propinsi Jambi, sebelah Timur berbatasan dengan Propinsi Jambi dan Sumatera Selatan, sebelah barat berbatasan dengan Kabupaten Bengkulu Utara, dan sebelah selatan berbatasan dengan Kabupaten Rejang Lebong.

Dengan kondisi seperti ini, maka Kabupaten Lebong terkenal sebagai daerah yang memiliki sumber daya alam yang melimpah. Keanekaragaman flora dan faunanya dan sumber daya alamnya dapat mencukupi kehidupan rakyatnya seperti produk pertanian (beras, kopi, dan minyak nilam), perikanan (terutama ikan mas), dan

\footnotetext{
${ }^{1}$ Profil Kawasan Kabupaten Lebong, http://profilkawasan.blogspot.co.id/2015/05/profilkabuapten-lebong.html
} 
sektor pertambangan (seperti emas, batu kapur, marmer dan sebagainya).

Sumber daya alam lainnya yang tidak terdapat di Kabupaten lain di Propinsi Bengkulu namun ada di Kabupaten Lebong adalah energi panas bumi (geothermal). Energi panas bumi yang merupakan energi terbarukan dapat digunakan untuk berbagai keperluan terutama kebutuhan listrik. Energi panas bumi merupakan energi alternatif karena menipisnya energi minyak dan gas bumi. Penggunaan batu bara yang merusak lingkungan dianggap tidak dapat menggantikan minyak dan gas bumi, sehingga manusia berupaya untuk mencari sumber energi lain. Apalagi dalam kondisi semakin meningkatnya kebutuhan energi dunia dari tahun ke tahun, serta tuntutan untuk melindungi bumi dari pemanasan global, pencemaran dan perusakan lingkungan hidup membuat masyarakat berupaya untuk segera mewujudkan teknologi baru sebagai sumber energi yang terbaharukan. Sumber energi baru yang terbaharukan itu adalah energi panas bumi (geothermal).

Dan yang paling penting Energi panas bumi merupakan sumber energi lokal yang tidak dapat di ekspor dan sangat ideal untuk mengurangi peran bahan bakar fosil guna meningkatkan nilai tambah nasional dan merupakan sumber energi yang ideal untuk pengembangan daerah setempat. Selain itu, energi panas bumi adalah energi terbarukan yang tidak tergantung pada iklim dan cuaca, sehingga keandalan terhadap sumber energinya tinggi. ${ }^{2}$

Energi panas bumi ditemukan di enam lokasi di wilayah Kabupaten Lebong, yaitu di sekitar Desa Sukaraja, ujung Sungai Ketahun, di Air Kopras, di sekitar transmigrasi Ladang Palembang dan Lebong Sulit serta di Ulu Lais. ${ }^{3}$

Pemanfaatan energi panas bumi di desa Talang Sakti, Hulu Lais Kecamatan Lebong Tengah Kabupaten Lebong dilaksanakan oleh PT Pertamina Geothermal Energy Hulu Lais (PT PGE Hulu Lais) berdasarkan SK Kelayakan Lingkungan nomor 793 tahun 2008 tanggal 18 oktober 2008, namun baru beroperasi sejak tahun 2012. PT PGE Hulu Lais mulai menggarap cadangan gas panas bumi ini dengan besar cadangan sekitar 650 Mega Watt Energi (MWE). Sedangkan berdasarkan hasil survei Dinas ESDM Provinsi Bengkulu, cadangan gas alam di daerah itu ditaksir bisa menghasilkan sekitar 1.073 MWE yang terdapat di tiga lokasi,

\footnotetext{
${ }^{2}$ Ibid.

${ }^{3}$ Tun Lebong's Weblog, Pertamina Mulai Garap cadangan Panas Bumi di Lebong, https://lebong.wordpress.com/2008/02/08/pertaminamulai-garap-cadangan-panas-bumi-di-lebong/
} 
disamping cadangan gas alam berkapasitas besar lainnya. ${ }^{4}$

Dari proyek energi panas bumi ini diharapkan mampu menyumbang listrik sebesar 1 x 55 MW pada Januari 2018 dan tambahan 1 x 55 MW pada Desember 2019. Harapan ini disebabkan potensi besar yang terdapat di lokasi ini, dan PT PGE menggarap proyek ini berdasarkan cluster-cluster. Dijelaskan oleh Humas PT. PGE yaitu Lukman H.S, saat ini ada 8 Cluster yang sudah dibangun yaitu Cluster A,B,C,D,E,M,P dan Q) dengan masing-masing cluster luasnya mencapai 4-5 Ha. Setiap cluster terdiri dari 3 hingga 4 sumur, sehingga jumlah sumur ada sekitar 32 buah. Sebelum dijadikan pembangkit listrik, ada 3 tahap proses yang di lakukan pihak PT.PGE Hulu Lais, diantaranya tahap eksplorasi, eksploitasi dan pengembangan. Sampai saat ini, proyek ini masih berstatus eksplorasi yang di prediksi hingga 2 tahun kedepan. ${ }^{5}$

Eksplorasi energi panas bumi adalah kegiatan yang dapat menimbulkan dampak kepada lingkungan hidup di sekitarnya, seperti timbulnya getaran ketika mesin-mesin sedang

\footnotetext{
${ }^{4}$ Merdeka.com, Pertamina Mulai Garap Cadangan Panas Bumi di Lebong, https://www.merdeka.com/uang/pertamina-mulaigarap-cadangan-panas-bumi-di-lebong-qgvufwl.html ${ }^{5} \mathrm{RMol}$ Bengkulu, Ini Potensi geothermal di kabupaten Lebong, http://www.rmolbengkulu.com/read/2016/05/11/860/Ini -Potensi-Energi-Geothermal-di-Kabupaten-Lebong-
}

bekerja, kotornya sumber air minum, udara yang bertambah panas, timbulnya asap dan sebagainya. Beberapa desa yang berada di sekitar lokasi PT PGE Hulu Lais dan berpotensi untuk terkena dampak dari kegiatan PT PGE Hulu Lais adalah : Desa Danau Liang, dan Desa Semalako yang berada di kecamatan Lebong tengah, desa Taba Anyar, desa Mubai, desaTes, desa Turan Lalang, desa mania Blau, desa Tik Jeriak, dan beberapa desa lainnya. ${ }^{6}$

Setelah 4 tahun beroperasi, pada bulan April 2016, terjadi musibah longsor akibat hujan deras di Lokasi cluster A. Longsor ini mengakibatkan tiga orang tewas yang merupakan karyawan dari PT PGE Hulu Lais sendiri, (namun merupakan penduduk desa setempat), empat orang hilang dan beberapa orang luka-luka. Selain kerugian jiwa dan luka-luka, masyarakat juga menderita kerugian berupa tertimbunnya kolam ikan, ${ }^{7}$ gagalnya panen kopi, serta tertimbunnya sumber air bersih milik warga. ${ }^{8}$

${ }^{6}$ Berdasarkan wawancara dengan warga desa Danau Liang dan wawancara dengan Kepala Bidang Pengedalian dan Pencemaran Lingkungan Hidup Dinas Lingkungan Hidup Kabupaten Lebong pada Kamis, 5 Oktober 2017.

${ }^{7}$ Suara pedia.com, Warga semakin Menderita, Proses Ganti rugi PT PGE Hulu Lais tidak jelas, http://suarapedia.com/id-467-post-warga-makinmenderita-proses-ganti-rugi-pt-pge-hululais-takjelas.html

${ }^{8}$ Berdasarkan wawancara dengan warga masyarakat desa Danau Liang Kecamatan Lebong Tengah Kabupaten Lebong pada Rabu 4 Oktober 2017. 
Peristiwa tersebut menyebabkan timbulnya masalah antara warga dari beberapa desa yang menjadi korban longsoran dengan PT PGE Hulu Lais. Warga desa menghendaki adanya ganti rugi terhadap kerugian materil yang mereka derita. Sementara terhadap tiga korban yang meninggal, PT PGE Hulu Lais telah menyerahkan santunan berupa uang sejumlah Rp. 103.800.000,00 kepada para ahli waris korban. ${ }^{9}$ Namun terhadap kerugian lainnya belum ada ganti rugi yang memadai.

\section{Pembahasan}

\section{A. Permasalahan hukum yang dihadapi oleh masyarakat di desa-desa sekitar PT PGE Hulu Lais menurut hukum lingkungan}

\section{Percemaran Lingkungan Hidup}

Berdasarkan wawancara dengan penduduk desa Danau Liang, diketahui bahwa sejak beroperasinya PT PGE Hulu Lais, ada beberapa hal yang terjadi yang dapat digolongkan sebagai pencemaran lingkungan hidup, yaitu ;

\section{a. Tercemarnya sumber air minum di desa Danau Liang dan Danau Lupang $^{10}$}

\footnotetext{
${ }^{9}$ Rakyat Bengkulu, Korban longson PT PGE akhirnya menerima santunan, http://harianrakyatbengkulu.com/ver3/2016/10/07/korba n-longsor-pt-pge-akhirnya-terima-santunan/

${ }^{10}$ Wawancara dengan warga desa danau Liang, 4 Oktober 2017.
}

Berdasarkan penuturan warga, sumber mata air desa yang merupakan sumber air minum mereka telah tercemar. Pencemaran sumber air minum tersebut meliputi kondisi air yang berbusa, berbau dan berwarna hitam. Sumber mata air lainnya terdapat di desa Danau Lupang mengalami hal yang sama. Kedua sumber mata air ini terletak berdekatan dengan cluster P yang sedang beroperasi.

Menurut penduduk desa Danau Liang dan danau Lupang, mata air yang menjadi sumber air minum yang kemudian dikelola oleh PDAM ini telah mereka gunakan selama bertahun-tahun. Namun hal seperti ini baru terjadi semenjak PT PGE Hulu Lais beroprasi, sehingga mereka menduga ada hubungan erat antara pencemaran sumber air minum mereka dengan kegiatan operasi PT PGE Hulu Lais.

Masalah ini kemudian diadukan warga ke Kantor PGE Hulu Lais, dan pihak PT PGE Hulu Lais melakukan beberapa hal, yaitu: (1) Melakukan penyemprotan pada lokasi air yang berbusa menggunakan defoamer; (2) Mengambil sampel air untuk dianalisa di laboratorium; (3) Berjanji akan melakukan pemantauan air di danau Lupang secara rutin dan berkala. 
Selain membawa masalah tersebut ke PT PGE Hulu Lais, warga penduduk desa Danau Liang dan Danau Lupang juga mengadalan pengaduan ke Kantor Dinas Lingkungan Hidup Kabupaten Lebong pada hari Sabtu 4 Februari 2017, dimana pengaduan yang disampaikan oleh warga desa tersebut diterima baik oleh petugas dan segera dilakukan pengecekan.

Pada tanggal 13 Februari 2017 Tim Kantor Dinas Lingkungan Hidup Kabupaten Lebong mengadakan pengecekan ke sumber air minum di desa Danau Liang dan Danau Lupang dan menemukan beberapa hal sebagai berikut:

1) Saat Tim tiba di lokasi, ternyata cluster P dari PT PGE Hulu Lais sedang tidak beroperasi;

2) Kondisi air PDAM di desa danau Liang dan Danau Lupang tidak berbau, tidak berbusa dan tidak berwarna hitam dengan derajat keasaman $(\mathrm{pH})$ dalam rentang 6-7,5 (normal);

3) Tidak ada kekeringan yang terjadi di sekitar sumber air PDAM Danau Lupang seperti yang telah dilaporkan sebelumnya.

4) Tim juga mengambil sampel air dan akan dianalisis di Laboratorium Palembang (Karena laboratorium ini belum tersedia di kabupaten Lebong).
Dari pengecekan di lokasi yang dilakukan oleh Tim Kantor Dinas Lingkungan Hidup Kabupaten Lebong terlihat adanya ketidaksinkronan antara laporan warga dengan kondisi yang ditemukan Tim di lapangan. Namun hal itu tidak berarti bahwa tidak terjadi pencemaran seperti yang dilaporkan warga, karena berdasarkan laporan Tim dari kantor Dinas lingkungan Hidup Kabupaten Lebong bahwa mereka mendatangi Lokasi ketika sedang tidak ada kegiatan PT PGE Hulu Lais, maka ada beberapa hal yang dapat dianalisis, yaitu ;

1) Pada waktu tersebut kondisi tanah sedang tenang sehingga tidak berpengaruh kepada sumber air minum PDAM Danau Liang dan Danau Lupang. Hal ini diperkuat dari keterangan warga Danau Liang ${ }^{11}$ bahwa air akan menjadi keruh dan berwarna hitam ketika mesinmesin PT PGE Hulu Lais bekerja sehingga berkemungkinan mengakibatkan naiknya lumpur dan sedimen lain dari dasar sumber air. Begitu pula air yang berbusa berasal dari buangan yang dikeluarkan oleh pipapipa PT PGE Hulu Lais ketika beroperasi, sehingga mengakibatkan

\footnotetext{
${ }^{11}$ Wawancara pada hari Rabu tanggal 4 Oktober 2017.
} 
sumber air minum warga jadi berbusa dan berbuih.

2) Kekeringan yang terjadi di sekitar sumber air desa Danau Lupang juga tidak terbukti karena menurut warga kekeringan baru terjadi jika mesin-mesin PT PGE Hulu Lais menyemburkan uap panas, yang kadang berwarna putih kadang berwarna hitam. Namun jika mesin-mesin tersebut berhenti beroperasi selama beberapa hari maka kondisi kekeringan tidak terjadi lagi.

\section{b. Berubahnya air kolam ikan warga :}

Demikian pula masalah yang sama juga menimpa warga desa Semelako. Air pada kolam ikan milik penduduk berubah warna menjadi hitam, berbau dan berbusa, padahal perikanan kolam adalah sumber utama mata pencarian penduduk warga desa Semelako. ${ }^{12}$

\section{c. Semburan uap panas dari proses pengeboran :}

Semburan uap panas dari proses pengeboran PT PGE, mengakibatkan mengeringnya tanah sawah dan kebun milik warga di desa Bukit Nibung Kecmamatan Bingin Kuning. Puluhan hektar tanah sawah dan kebun menjadi tandus dan kering akibat semburan uap

${ }^{12}$ Wawancara dengan petugas Dinas Lingkungan Hidup kabupaten Lebong, Kamis, 5 Oktober 2017. panas dari aktivitas uji cluster PT PGE. Tanah sawah dan kebun yang tadinya subur sekarang berubah menjadi kering kerontang. ${ }^{13}$

\section{Kerusakan Lingkungan Hidup}

Masalah hukum lain yang muncul sebagai akibat dari beroperasinya PT PGE Hulu Lais adalah masalah kerusakan lingkungan hidup. Berdasarkan kondisi di lapangan dan wawancara dengan warga diketahui ada beberapa kerusakan lingkungan hidup, yaitu :

\section{a. Longsornya tanah di cluster A :}

Longsornya tanah di cluster A mengakibatkan 6 orang meninggal dunia (1 orang merupakan pekerja PT PGE Hulu Lais yang merupakan warga desa setempat dan 5 lainnya warga setempat), 3 orang luka-luka, dan kerugian materil ditaksir sekitar 40 milyar rupiah. ${ }^{14}$ Hujan deras yang turun beberapa hari mengakibatkan tebing danau bukit belerang longsor yang berjarak sekitar $2 \mathrm{~km}$ dari pengeboran cluster A. Menurut pihak PT PGE Hulu Lais, longsor terjadi disebabkan struktur tanah yang longggar, sehingga ketika turun

\footnotetext{
${ }^{13}$ Rakyat Bengkulu, Dampak Aktivitas PT PGE, sawah warga tandus, http://harianrakyatbengkulu.com/ver3/2017/07/24/damp ak-aktivitas-pge-sawah-warga-tandus/

${ }^{14}$ Semaraknews.co.id, Dampak longsor PT PGE Kerugian diperkirakan $40 \quad$ Milyar, http://www.semaraknews.co.id/2016/05/kerugianmusibah-longsor-pge-di-lebong-tahun-2016.html
} 
hujan lebat maka terjadi longsor. Sebaliknya warga tidak sependapat. Menurut warga, ketika mesin-mesin PT PGE Hulu Lais beroperasi, warga merasa tanah bergetar seperti gempa, sehingga sudah menduga akan terjadinya longsor seperti ini. ${ }^{15}$

\section{b. Tertimbunnya lahan sawah dan} kebun warga :

Longsornya tanah di cluster A juga berakibat pada lahan persawahan dan kebun warga. Beberapa hektar sawah dan kebun warga tertimbun lumpur yang berasal dari longsoran bukit Beliti cluster A. Hal ini mengakibatkan warga tidak dapat bekerja untuk memenuhi kebutuhan hidupnya. Bahkan ada beberapa lahan sawah dan kebun sudah bersiap untuk panen, namun tertimbun lumpur sehingga sawah dan kebun menjadi gagal panen.

\section{c. Pengerukan sungai Kotok yang merusak ekosistem sungai :}

Akibat adanya pengerjaan proyek pengerasan jalan oleh PT PGE Hulu Lais, maka ekosistem sungai Kotok mengalami kerusakan. Hal ini disebabkan karena material yang digunakan untuk membuat jalan tersebut diambil dari sungai Kotok, maka dalam proses pengerukan material

${ }^{15}$ Berdasarkan wawancara dengan warga Desa danau Liang 4 Oktober 2017. tersebut sangat mengganggu dan merusak ekosistem dan habitat ikan dan tumbuhan yang ada di dasar dan pinggir sungai. Akibatnya kondisi sungai Kotok sudah berubah, mengalami banyak lubang-lubang di pinggirnya dan air sungainya pun menjadi keruh. Selain itu juga terlihat ikanikan kecil yang mati mengambang karena terkena alat berat.

\section{d. Keringnya air sungai Mubai :}

Masyarakat di Kecamatan Lebong Selatan, khususnya di Kelurahan Mubai mengeluhkan saat ini aliran air sungai itu kering. Padahal warga memanfaatkan air sungai itu untuk keperluan sehari-hari, seperti mencuci, mandi dan untuk air minum. Di saat musim penghujan biasanya debit air sungai semakin tinggi, namun yang terjadi justru air sungai mengering. Hal tersebut terjadi diduga akibat air Sungai Mubai disedot oleh PT PGE Hulu Lais Kabupaten Lebong, untuk aktivitas pengeboran. Hal ini dibenarkan oleh Menejer Proyek PT PGE, bahwa untuk melakukan operasinya, PT PGE menggunakan air sungai Mubai.

\section{e. Keringnya sawah dan kebun :}

Saat ini lebih dari 20 hektar lahan persawahan dan kolam ikan warga di Kelurahan Mubai yang selama ini pengairannya mengandalkan air sungai 
Mubai tidak lagi mendapatkan air. ${ }^{16}$ Selain itu, menurut warga desa Danau Liang, tanaman kopi beserta tumbuhan lain yang berada di sekitar sumber air Danau Lupang mulai mengering dan mati, sehingga mereka mengalami gagal panen dari tumbuhan kopi mereka. ${ }^{17}$

Dari beberapa permasalahan yang sudah diuraikan di atas terlihat bahwa warga di beberapa desa di Kabupaten Lebong saat ini menderita kerugian baik secara moril maupun materil. Warga desa di Kabupaten Lebong hanya mengandalkan tanah sawah dan kebun mereka sebagai sumber penghasilan. Oleh karena itu warga merasa keberatan dengan kegiatan yang dilakukan oleh PT PGE, sehingga warga telah beberapa kali mengajukan pengaduan, baik ke Kantor Dinas Lingkungan Hidup Kabupaten Lebong, maunpun ke DPRD Lebong, namun hasil yang diharapkan belum terlihat.

\section{B. Perlindungan hukum terhadap} masyarakat di sekitar kegiatan PT PGE Hulu Lais menurut Hukum Lingkungan

\section{Pihak yang harus bertanggungjawab:}

Kepala Badan Lingkungan Hidup Kebersihan dan Pertamanan (BLHKP)

\footnotetext{
${ }^{16}$ Bengkulu Ekspress.com, Sungai Mubai kering, http://bengkuluekspress.com/sungai-mubai-kering/

${ }^{17}$ Wawancara dengan warga Danau Liang pada hari Rabu, 4 Oktober 2017.
}

Kabupaten Lebong Zamhari Bahrun menilai, kejadian longsor dan banjir bandang di Cluster A pengeboran panas bumi milik PT PGE Hulu Lais beberapa waktu lalu merupakan kelalaian pihak perusahaan. Karenanya, terkait dampak yang ditimbulkan oleh kelalaian itu adalah tanggung jawab PT PGE. ${ }^{18}$

Pernyataan yang dikeluarkan oleh Kepala BLHKP ini berbeda dengan yang dikeluarkan oleh Kepala Pusat Data Informasi dan Humas Badan Nasional Penanggulangan Bencana Sutopo Purwo Nugroho, bahwa Longsor tidak ada kaitannya dengan aktivitas geothermal. Longsor disebabkan oleh faktor alam yang meluncur menuruni perbukitan dan menghantam kamp pekerja. ${ }^{19}$

Namun berdasarkan fakta di lapangan dapat diketahui bahwa kondisi ini terjadi bukan karena faktor alam semata. Artinya, PT PGE Hulu Lais tetap memiliki andil atas terjadinya bencana ini, sehingga harus bertanggungjawab terhadap semua pencemaran dan kerusakan lingkungan

\footnotetext{
${ }^{18}$ Radar Pat petulai, Kerusakan Lahan tanggungjawab $P T \quad P G E$, http://www.radarpatpetulainews.com/2016/07/kerusaka n-lahan-tanggung-jawab-pge.html

${ }^{19}$ Okezone, PT PGE berjanji memberi bantuan kepada korban longsor Lebong, https://news.okezone.com/read/2016/04/29/340/137581 8/pt-pge-janji-beri-bantuan-pada-korban-longsor-dilebong
} 
hidup yang menimpa warga di beberapa desa di kabupaten Lebong. Oleh karena itu, sesuai dengan asas yang berlaku dalam UUPPLH, yaitu asas pencemar membayar, maka PT PGE Hulu Lais harus bertanggungjawab untuk memberikan ganti rugi terhadap kerugian yang telah diderita oleh warga. Hal yang sama juga dinyatakan oleh Kementerian Lingkungan Hidup, bahwa PT PGE Hulu Lais adalah pihak utama yang menjadi penanggungjawab atas terjadinya longsor dan kerugian yang diderita oleh warga.

Adapun alasan yang dapat diberikan sehubungan dengan tanggungjawab yang harus dibebankan kepada PT PGE Hulu Lais adalah :

a. PGE telah mengetahui sejak awal bahwa kondisi geografis lokasi perusahaan itu berada di daerah rawan bencana. Hal ini terbukti dengan rencana upaya pengelolaan yang dicantumkan dalam Dokumen Rencana Pengelolaan yang menyatakan bahwa PT PGE akan membuat drainase yang mampu menahan air limpasan pada kondisi puncak curah hujan. Untuk mengurangi pengikisan lapisan tanah, saluran drainase pembuangan akan dibuat pada lereng yang landai dan dibuat bertingkat. ${ }^{20}$ Namun faktanya PT PGE Hulu Lais tidak ada membangun drainase-drainase dimaksud, sehingga ketika hujan turun dengan deras, terjadilah longsor yang memakan korban jiwa dan tertimbunnya swah dan kebun warga dengan lumpur.

b. PT PGE melanggar sendiri janjinya yang tercantum dalam Rencana Pengelolaan yang menyatakan akan membuat gorong-gorong oada daerah rendahan, membuat teras bangunan konservasi terutama pada lahan lereng8-15\%, tidak membuang limbah kimia di daerah resapan air, dan beberapa rencana lain yang tidak terlaksana, terbukti dari tercemarnya sumber air minum warga.

c. PT PGE juga tidak melaksanakan rencananya mengenai tidak menutup saluran air alami (sungai), namun faktanya menyedot air sungai Mubai untuk kegiatan operasi sehingga air sungai Mubai menyusut dan tidak dapat mengairi sawah warga.

2. Perlindungan hukum terhadap masyarakat di sekitar kegiatan PT PGE Hulu Lais menurut Hukum Lingkungan

\footnotetext{
20 Tabel 1 Matriks rencana Pengelolaan Kegiatan Pembangunan Lapangan Panas Bumi dan Pembangkit Tenaga Panas bumi (PLPT) Hulu Lais PT Pertamina Geothermal Energy.
} 
Berdasarkan UUPPLH, untuk menyelesaikan kasus ini ada beberapa langkah yang dapat diambil dalam upaya memberikan perlindungan hukum kepada warga yang menderita kerugian akibat kegiatan PT PGE Hula Lais. Adapun langkah-langkah tersebut adalah:

\section{a. Penyelesaian sengketa secara hukum perdata :}

Menurut pasal 84-86 UUPPLH, penyelesaian sengketa secara perdata dapat ditempuh melalui 2 cara yaitu :

1) Penyelesaian sengketa di luar Pengadilan;

2) Penyelesaian sengketa melalui Pengadilan.

Penyelesaian sengketa di luar Pengadilan ditujukan untuk membuat kesepakatan mengenai bentuk dan besar ganti rugi. Pada tahap ini para pihak dapat berunding untuk menentukan ganti rugi yang diinginkan, baik berunding tanpa pihak ketiga maupun berunding dengan bantuan pihak ketiga.

Berdasarkan faktanya maka diketahui bahwa pihak-pihak telah sepakat untuk menyelesaikan sengketa di luar pengadilan, terbukti pada bulan Maret 2017 sebanyak 41 Kepala Keluarga (KK) korban telah menerima ganti rugi yang diberikan oleh pihak PT
PGE Hulu Lais melalui rekening Bank setelah terciptanya kesepakatan nilai kompensasi dengan ganti rugi sebesar Rp 9,5 Juta perHa yang di fasilitasi Pemkab Lebong. ${ }^{21}$

Walaupun demikian ternyata banyak warga yang tidak setuju dengan jumlah ganti rugi sebesar Rp 9,5 juta per Ha, sehingga banyak yang tidak bersedia mengambil uang ganti rugi tersebut. Berdasarkan hal tersebut, Bupati Lebong mengirimkan surat kepada PT PGE Hulu Lais agar PT PGE menambah jumlah uang ganti rugi menjadi Rp 10,7 Milyar, yang pada 18 Mei 2017 kemudian disepakati oleh PT PGE setengahnya, yaitu 5, 35 Milyar rupiah. Namun pembagian uang ini tidak transparan dan merata sehingga menuai protes lagi dari warga. $^{22}$

Menurut UUPPLH jika pihakpihak tidak dapat menyelesaikan sengketa mereka melalui jalur di luar pengadilan, maka mereka dapat menyelesaikan sengketa melalui

\footnotetext{
${ }^{21}$ RMol Bengkulu, Korban Uji Produksi PT PGE terima ganti rugi, http://www.rmolbengkulu.com/read/2017/04/03/3936/K orban-Uji-Produksi-PT-PGE-Lebong-Terima-Ganti-

Rugi-

${ }^{22}$ Media Indonesia, Bantuan untuk korban longsor Lebong tidak transparan, http://www.mediaindonesia.com/news/read/106708/ban tuan-untuk-korban-longsor-lebong-tidak$\underline{\text { transparan/2017-05-29 }}$
} 
pengadilan. Jika pengadilan mampu membuktikan terjadinya pencemaran dan/atau kerusakan lingkungan hidup yang mengakibatkan kerugian kepada masyarakat, maka pengusaha wajib membayar ganti rugi atau melakukan tindakan tertentu seperti memulihkan kondisi lingkungan seperti semula. ${ }^{23}$

Pengajuan gugatan secara perdata ke Pengadilan dapat diajukan oleh kelompok masyarakat yang dirugikan, Lembaga Swadaya Masyarakat (LSM), Pemerintah dan/atau Pemerintah Daerah. $^{24}$ Artinya gugatan secara perdata hanya bias dilakukan secara bersama-sama dan atas nama kelompok atau Pemerintah, tidak dapat diajukan oleh orang perorangan. Jika gugatan diterima hakim, maka kelompok masyarakat dapat menerima ganti rugi berupa uang, sesuai keputusan hakim, namun LSM dilarang oleh UUPPLH untuk menerima ganti rugi berupa uang, melainkan berupa tindakan tertentu. Jika pengusaha terlambat dalam membayar ganti rugi maka hakim dapat menetapkan uang paksa (dwangsom).

\section{b. Penyelesaian sengketa secara hukum administrasi:}

\footnotetext{
${ }^{23}$ Pasal 87 UUPPLH.

${ }^{24}$ Pasal 90,-92 UUPPLH.
}

Menurut pasal 93 UUPPLH, setiap orang dapat mengajukan gugatan administrasi ke Pengadilan Tata Usaha Negara. Gugatan ditujukan kepada pemerintah atau Pemerintah Daerah sebagai badan yang berwenang untuk menerbitkan izin lingkungan. Gugatan dapat diajukan jika :

1) Kegiatan/usaha tidak dilengkapi dokumen AMDAL;

2) Kegiatan/usaha tidak dilengkapi UKLUPL;

3) Kegiatan/usaha tidak dilengkapi izin lingkungan.

Dalam kasus PT PGE Hulu Lais ini, terbukti bahwa kegiatan ini telah mendapatkan izin dari Bupati Lebong melalui Keputusan Bupati Lebong nomor 793 tahun 2008 tentang Kelayakan Analisa Dampak Lingkungan (ANDAL) Rencana Pengelolaan Lingkungan (RPL) Rencana Pemantauan Lingkungan (RPL) Kegiatan Pembangunan Lapangan Panas bumi dan pembangkit Listrik tenaga Panas bumi Hulu Lais oleh PT Pertamina Geothermal Energy di Kecamatan Lebong Tengah dan Kecamatan Lebong Selatan Kabupaten Lebong, dan melalui Surat Keputusan ini Bupati Lebong menyatakan bahwa kegiatan ini layak dilakukan ditinjau dari aspek lingkungan hidup. 
Namun yang perlu dipertanyakan disini adalah :

1) Apakah Andal tersebut memang benar-benar sudah layak dan memenuhi criteria yang telah ditetapkan menurut Undangundang?

2) Apakah dalam pembuatan Andal, RKL dan RPL ini PT PGE Hulu Lais melibatkan peran masyarakat setempat, sesuai yang diatur dalam pasal 26 UUPPLH? Tujuannya adalah agar masyarakat diberi informasi yang transparan dan lengkap sebelum kegiatan dilaksanakan.

Berdasarkan aturan pasal 76 UUPPLH, jika secara administrasi pemerintah/pemerintah daerah menganggap kegiatan usaha melakukan pelanggaran terhadap izin lingkungan, maka pemerintah/pemerintah daerah dapat menjatuhkan sanksi administrasi kepada perusahaan, berupa : (1) Teguran tertulis; (2) Paksaan pemerintah; (3) Pembekuan izin lingkungan; (4) Pencabutan izin lingkungan. Berdasarkan wawancara dengan Kepala Bidang Penataan dan Pentaatan Peraturan Lingkungan Hidup Dinas Lingkungan
Hidup ${ }^{25}$ maka ada beberapa langkah yang telah diberikan kepada PT PGE Hulu Lais, yaitu : pertama, Teguran tertulis, berupa peringatan bahwa PT PGE telah melakukan sesuatu yang berakibat kerugian bagi warga sekitar; kedua, Paksaan pemerintah, berupa : a) Perintah kepada PT PGE untuk melakukan pengecekan terhadap sumber air warga minimal sekali setiap tri wulan; b) Perintah untuk melakukan normalisasi sumber air warga yang tercemar; c) Perintah kepada PT PGE untuk memberikan bantuan kepada warga yang tidak dapat memanfaatkan sumber air dengan mendatangkan truk berisi air bersih.

Berdasarkan tindakan-tindakan yang telah dilakukan tersebut, terlihat Dinas Lingkungan Hidup Kabupaten Lebong telah berusaha untuk menegakkan aturan Hukum Lingkungan di bidang administrasi, sehingga diharapkan peranan pemerintah seperti ini terus berlanjut agar ada pengawasan terhadap setiap kegiatan usaha, sehingga masyarakat merasa terlindungi oleh Pemerintah Daerah.

\section{c. Penegakan hukum dari aspek hukum pidana :}

Penegakan hukum lingkungan dari aspek pidana bertujuan agar perlindungan dan pengelolaan lingkungan hidup dapat

\footnotetext{
${ }^{25}$ Wawancara pada hari Kamis, 5
} Oktober 2017. 
berjalan sesuai dengan tujuannya. Penegakan hukum lingkungan dari aspek hukum pidana dilaksanakan oleh aparat penegak hukum pidana, seperti Kepolisian dan Jaksa. Di samping itu, aparat lainnya adalah PPNS (Penyidik Pegawai Negeri Sipil). PPNS memiliki kewenangan penyidikan yang sama dengan petugas kepolisian, sehingga kedua aparat tersebut dapat bekerjasama dan tunduk pada ketentuan Hukum Acara Pidana yang berlaku.

Pada kasus longsornya tanah di cluster A PT PGE Hulu Lais yang mengakibatkan hilangnya 6 nyawa manusia, maka disini telah terpenuhi unsurunsur tindak pidana. Dalam pasal 97 UUPPPLH dinyatakan bahwa tindak pidana lingkungan adalah kejahatan. Artinya tidak memandang apakah perbuatan itu sebagai akibat kelalaian atau kesengajaan, maka perbuatan itu adalah kejahatan.

Berdasarkan ketentuan tersebut maka PPNS terkait dapat melakukan tindakan penyidikan untuk menegakkan aspek hukum pidana lingkungan. Agar tindakan penyelidikan terhadap kegiatan usaha dapat berjalan baik dan maksimal, maka diperlukan sumber daya manusia yang berkualitas dan dalam jumlah yang cukup. Hal inilah yang menjadi kendala pada
Dinas Lingkungan Hidup Kabupaten Lebong, yaitu tidak adanya tenaga PPNS, sehingga tindakan penyidikan terhadap PT PGE Hulu Lais masih terkendala. Akibatnya sampai saat ini belum ada tindakan penyidikan tindak pidana sehubungan dengan terjadinya longsor akibat kegiatan PT PGE Hulu Lais.

\section{Penutup}

Kesimpulan yang didapatkan yakni, ada beberapa macam masalah hukum lingkungan yang dihadapi oleh masyarakat desa-desa di sekitar kegiatan PT PGE Hulu Lais, yaitu :

a. Pencemaran lingkungan hidup yang terjadi akibat longsornya bukit di cluster A kegiatan PT PGE Hulu Lais, yang terdiri dari :

1) Pencemaran sumber air minum di desa Danau Liang dan Danau Lupang;

2) Pencemaran air kolam ikan warga yang menyebabkan ikan-ikan mati;

3) Gagal panen dari beberapa kebun seperti kebun kopi, palawija dan sebagainya karena kekeringan sebagai akibat semburan uap panas dari kegiatan PT PGE

b. Perusakan lingkungan hidup, yang terjadi karena longsornya bukit di cluster A kegiatan PT PGE Hulu Lais, yang terdiri dari : 
1) Tertimbunnya kolam ikan, sawah dan kebun warga di beberapa desa seperti desa Semelako, desa Taba Anyar dan desa Mubai;

2) Rusaknya ekosistem di sungai Kotok;

3) Keringnya air sungai Mubai;

4) Keringnya lahan sawah dan kebun.

Perlindungan hukum yang dapat diberikan kepada warga di desa-desa sekitar kegiatan PT PGE adalah : Penyelesaian sengketa secara hukum perdata berupa ganti rugi kepada para warga desa yang telah menderita kerugian; Penyelesaian sengketa secara hukum administrasi berupa gugatan ke PTUN mengenai perizinan dan penjatuhan sanksi administrasi kepada PT PGE berupa teguran tertulis dari DLH. Penegakan hukum dari aspek hukum pidana, yang sampai saat ini belum terlaksana karena belum adanya PPNS.

Adapun saran yang dapat diberikan yakni Warga diberi pemahaman akan hak dan kewajiban mereka terhadap lingkungan; Pengawasan terhadap PT PGE Hulu Lais agar diperketat terutama oleh DLH; Agar pemerintah menyediakan tenaga PPNS secepatnya.

\section{Daftar Pustaka}

A'an Efendi, 2012, Penyelesaian Sengketa Lingkungan, Mandar Maju, Bandung.
Bahan Ajar Bidang SKA Lemhannas RI 2015

Daud Silalahi, 2001, Hukum Lingkungan dalam Sistem Penegakan Hukum Lingkungan Indonesia, Alumni, Bandung.

Koesnadi Hardjasoemantri, 1986, Hukum Tata Lingkungan, Gadjah Mada University Press, Yogyakarta.

Muhammad Taufik Makarao, 2011, Aspekaspek Hukum Lingkungan, PT Indeks, Jakarta.

Takdir Rahmadi, 2011, Hukum Lingkungan di Indonesia, Raja Grafindo Indonesia, Jakarta.

\section{Peraturan Perundang-undangan}

Undang-undang Dasar Negara Republik Indonesia tahun 1945

Undang-undang nomor 32 tahun 2009 tentang Perlindungan dan Pengelolaan Lingkungan Hidup

\section{Jurnal, majalah, internet}

Anugrah Putra Ts, Potensi Energi Panas Bumi $d i$ Lebong, https://anugrahputratrisnasusila.wo rdpress.com/2015/02/09/potensienergi-panas-bumi-di-lebongkabupaten-kecil-bagian-dariprovinsi-bengkulu/

Bengkulu Ekspress.com, Sungai Mubai kering, http://bengkuluekspress.com/sunga i-mubai-kering/ 
Geothermal Indonesia, Manfaat Geothermal, https://geothermalindonesia.com/2 017/01/25/pemanfaatangeothermal-energi-panas-bumi/

Media Indonesia, Bantuan untuk korban longsor Lebong tidak transparan, http://www.mediaindonesia.com/n ews/read/106708/bantuan-untukkorban-longsor-lebong-tidaktransparan/2017-05-29

Merdeka.com, Pertamina Mulai Garap Cadangan Panas Bumi di Lebong, https://www.merdeka.com/uang/pe rtamina-mulai-garap-cadanganpanas-bumi-di-lebongqgvufwl.html

Okezone, PT PGE berjanji memberi bantuan kepada korban longsor Lebong, https://news.okezone.com/read/20 16/04/29/340/1375818/pt-pgejanji-beri-bantuan-pada-korbanlongsor-di-lebong

Profil Kawasan Kabupaten Lebong, http://profilkawasan.blogspot.co.id /2015/05/profil-kabuaptenlebong.html

Rakyat Bengkulu, Dampak Aktivitas PT PGE, sawah warga tandus, http://harianrakyatbengkulu.com/v er3/2017/07/24/dampak-aktivitaspge-sawah-warga-tandus/

Radar Pat petulai, Kerusakan Lahan tanggungjawab PT PGE, http://www.radarpatpetulainews.co $\mathrm{m} / 2016 / 07 /$ kerusakan-lahantanggung-jawab-pge.html

RMol Bengkulu, Ini Potensi geothermal di kabupaten Lebong, http://www.rmolbengkulu.com/rea d/2016/05/11/860/Ini-Potensi-
Energi-Geothermal-di-KabupatenLebong-

RMol Bengkulu, Korban Uji Produksi PT PGE terima ganti rugi, http://www.rmolbengkulu.com/rea d/2017/04/03/3936/Korban-UjiProduksi-PT-PGE-LebongTerima-Ganti-Rugi-

Semaraknews.co.id, Dampak longsor PT PGE Kerugian diperkirakan 40 Milyar, http://www.semaraknews.co.id/20 16/05/kerugian-musibah-longsorpge-di-lebong-tahun-2016.html

Suara pedia.com, Warga semakin Menderita, Proses Ganti rugi PT PGE Hulu Lais tidak jelas, http://suarapedia.com/id-467-postwarga-makin-menderita-prosesganti-rugi-pt-pge-hululais-takjelas.html

Tun Lebong's Weblog, Pertamina Mulai Garap cadangan Panas Bumi di Lebong, https://lebong.wordpress.com/200 8/02/08/pertamina-mulai-garapcadangan-panas-bumi-di-lebong/ 